REVISTA DE LITERATURA E CULTURA RUSSA

\title{
Formalismo Russo sob a lente de L. S. Vygótski: influência e crítica
}

\section{Russian Formalism through the lens of L. S. Vygotsky: influence and critic}

Autor: Priscila Nascimento Marques Edição: RUS Vol. 11. № 16

Data: Setembro 2020 


\section{O Formalismo Russo sob a lente de L. S. Vygótski: influência e crítica}

\section{Priscila Nascimento Marques*}

Resumo: 0 artigo apresenta a discussão vygotskiana sobre as ideias do Formalismo Russo expostas no capítulo "Arte como procedimento", do livro Psicologia da arte (de 1925).

Trata-se de uma resposta crítica contemporânea ao desenvolvimento da escola. Apesar de dialogar mais intimamente com as vertentes marxistas do estudo da arte em sua obra, Vygótski faz uma crítica muito refinada, que ressalta o potencial da Escola Formal e, ao mesmo tempo, aponta suas contradições e limitações, sem que as mesmas invalidem a profunda inovação, muito cara a Vygótski, oferecida por vertente dos estudos literários.

\begin{abstract}
The paper presents a discussion of the ideas of Russian Formalism by Vygotsky exposed in the chapter "Art as device", of the book The Psychology of art (1925). This is a critical response contemporaneous to the development of the aforementioned school. Despite the more intimate dialogue with Marxist approaches to the study of art in his work, Vygotsky makes a sophisticated criticism of the Formal School, one that enhances its potential and, at the same time, points to its contradictions and limitations without diminishing the originality of the approach to literary studies, which was so dear to Vygotsky.
\end{abstract}

Palavras-chave: L. S. Vygótski; Formalismo Russo; Psicologia da arte; Teoria literária; Reação estética.

Keywords: L. S. Vygotsky; Russian Formalism; Psychology of art; Literary theory; Aesthetic reaction. 


\section{Vigótski e a cultura literária russa}

* Mestra e doutora pelo Programa de Pós-Graduação em Literatura e Cultura Russa da Faculdade de Filosofia Letras e Ciências Humanas, Universidade de São Paulo. Realiza estágio de pós-doutorado no mesmo programa (Financiamento Fapesp: 2015/17830-1); https://orcid.org/0000-00027111-6372; prinmarques@ alumni.usp.br
Liev Semiónovitch Vygótski (1896-1934) notabilizou-se como um dos mais proeminentes e originais psicólogos soviéticos do início do século XX. Fato menos conhecido de sua biografia é seu intenso trabalho inicial no campo das artes, em particular com literatura e teatro. Filho de uma família judaica de classe média estabelecida em Gomel, na Bielorrússia, Vygótski recebeu sua educação inicial em casa com preceptores, e posteriormente em um Ginásio judaico para rapazes. O interesse por temas ligados à história e à filosofia surge ainda na juventude, como revela o testemunho do amigo Semión Dobkin, segundo o qual Vygótski liderou um grupo de estudos sobre história do povo judeu. Além disso, ainda aos 15 anos, Vygótski escreveu uma análise sobre a questão judaica na obra de Dostoiévski, o primeiro escrito de sua autoria de que se tem conhecimento. ${ }^{1}$

A partir de 1914, Vygótski ingressa na Universidade de Moscou e na Universidade Popular Chaniávski. Nessa última, sua formação em humanidades e filosofia ganha densidade, como se pode constatar na monografia escrita por Liev Semiónovitch como trabalho de conclusão de seus estudos na instituição. O ensaio "A tragédia de Hamlet, príncipe da Dinamarca" ${ }^{2}$ combina um interesse antigo de Vygótski - a tragédia shakespeariana foi desde a juventude até os últimos dias a grande obra fundamental de sua vida - com traços de uma formação literária e filosófica afeita ao Simbolismo recebida na Universidade Popular.

Nesse ensaio, Vygótski apresenta uma compreensão de Hamlet como mito: a tragédia é entendida como uma construção artística que revela algo sobre o caráter metafísico da existência humana. Ela oferece um sentido primeiro, derivado de sua construção formal e um segundo sentido, que não se pode apreender de todo, pois é inefável. O método de interpre-

1 Cf. DOBKIN, 1990.

2 Cf. VIGOTSKI, 1999. 
tação da tragédia desenvolvido nesse trabalho é denominado por Vygótski de crítica do leitor, uma crítica francamente subjetiva, embora não subjetivista, na medida em que, embora busque trazer à tona um entendimento pessoal da tragédia, tal entendimento deve ser fundamentado objetivamente, na materialidade da obra. Com efeito, trata-se de uma crítica algo impressionista, ainda que não chegue a se descolar da realidade do material literário, ao contrário, pois "se de um lado o crítico não está preso a nada no campo da obra em estudo - nem às concepções do autor, nem às opiniões de outros críticos -, de outro está inteiramente preso a essa mesma obra". ${ }^{3}$

O segundo sentido da tragédia, que é "sobrenatural e pertence ao mundo do além-túmulo"4 não é revelado pela crítica diretamente, mas apenas sentido conforme sua impressão nas palavras da tragédia. Como se pode observar, trata-se de uma perspectiva que compartilha dos pressupostos estéticos do simbolismo. Para essa corrente estética, o caráter simbólico da arte consiste em que esta é uma "ponte entre dois mundos", ${ }^{5}$ que evoca uma realidade mais profunda, inacessível diretamente. Outro traço simbolista da proposta vygotskiana reside na centralidade da subjetividade como norteadora da análise: a crítica do leitor, assim como a estética simbolismo, coloca o sujeito como centro da produção da arte e da possibilidade de entendê-la: "foi precisamente o simbolismo que problematizou a experiência da subjetividade acumulada no século XIX, e tentou desenvolvê-la, partindo de um princípio seu, o estetismo e a utopia conservadora, para outro - a revolução e a utopia liberal do futuro". ${ }^{6}$

A indelével marca do Simbolismo presente na monografia sobre Hamlet, escrita entre 1915 e 1916, não se apagará tão cedo. Vygótski continuará sendo um legítimo filho da Era de Prata mesmo depois de retornar a Gomel após 1917. São evidências disso o fato de que a empreitada de curto fôlego lan-

3 VIGOTSKI, 1999, p. XXII.

4 Idem, p. 8.

5 Berdiáiev apud CAVALIERI; VASSINA, 2005, p. 107.

6 TOLMACHOV, 2005, p. 32-33. 
çada por Vygótski em 1919 - a editora Veka i Dni (Eras e Dias) - teve apenas dois títulos lançados, um dos quais foi uma pequena antologia de versos do poeta greco-francês Jan Moréas (1856-1910), autor do Manifesto Simbolista (1886). Estava prevista ainda a publicação do também poeta simbolista Henri de Régnier (1864-1936).

Mais tarde, Vygótski se ocupará intensamente da publicação de crítica teatral. Trata-se de um vasto e fascinante corpus, no qual o autor se descola progressivamente da influência simbolista em favor de uma análise pouco subjetiva e mais pragmática e detalhada sobre as montagens teatrais apresentadas em Gomel. A primeira de suas críticas é publicada ainda em 1917, no periódico Liétopis de Moscou, mas a produção se intensifica entre 1922 e 1923, em jornais locais de Gomel. Na resenha sobre Monna Vanna, do expoente da dramaturgia simbolista Maurice Maeterlinck, por exemplo, Vygótski se limita a comentar a montagem em termos de sua adequação ao tom do "drama interior simbolista", ${ }^{7}$ isto é, seu exame do espetáculo não se vê imbuído de uma visão estética apriorística, mas busca revelar o quanto a peça é consistente com o estilo do texto levado ao palco.

Ainda nesse período pré-psicológico, Vygótski acompanhou como crítico teatral a ascensão das vanguardas russas. Escreveu resenhas sobre espetáculos da Mastfor, companhia de "dança excêntrica" de Nikolai Foregger, da companhia teatral Tocha Vermelha, do Segundo Estúdio do Teatro de Arte de Moscou, entre outros. Ainda antes da fase de crítica teatral gomeliana, Vygótski publicou em 1919 na antologia Versos e prosa sobre Revolução Russa um capítulo intitulado "Teatro e revolução". Nele, Liev Semiónovitch comenta as relações entre o fenômeno social e histórico da Revolução e os palcos russos, tanto em busca de indícios do teatro pré-1917 que pudessem prenunciar o fato revolucionário, como em termos das consequências deste para a cena.

Em "Teatro e revolução", Vygótski mostra-se um observador sensível e crítico às novas tendências estéticas, e reconhece

7 Cf. VYGÓTSKI, 1922, p. 8. 
na recém-publicada peça de Maiakóvski, Mistério-bufo (de 1918), a mais genuína expressão do novo tempo, uma obra que "nasceu do espírito da contemporaneidade"8. O autor aparece integralmente imbuído pela reviravolta produzida pelo acontecimento revolucionário de 1917 e olha o teatro sob as lentes da potencialidade de produção de novas formas: "[...] o espírito novo busca novas formas de se encarnar, assim como não se deve colocar vinho novo em odre velho"9.

Assim, no campo das artes Vygótski aparece como uma figura extremamente atenta aos fenômenos contemporâneos, com uma percepção aguçada acerca das relações entre arte e sociedade, distinta de uma leitura marxista vulgar de tipo sociologizante, que busca o reflexo decalcado dos processos sociais na produção artística. Ao contrário, o jovem crítico mostra compreender a interdependência entre arte e sociedade num nível propriamente estético, isto é, como produção de novas formas (e não incorporação de novos conteúdos) que respondam ao Zeitgeist.

Conhecedor dos desdobramentos vanguardistas na arte, Vygótski esteve a par também dos novos desenvolvimentos no campo teórico. Se a resposta à arte simbolista foi dada pelas vanguardas, particularmente pelo Cubofuturismo, no campo teórico isso se deu com o advento da chamada Escola Formal dos estudos literários, a qual será objeto de comentário por parte de Vygótski em sua obra Psicologia da arte, de 1925.

Esta seção pretendeu descrever de forma resumida o trabalho de Vygótski como crítico, enfatizando seu interesse não apenas pela arte canônica, mas pela nova arte vanguardista, com destaque também para o deslocamento de seu interesse do paradigma simbolista para a arte revolucionária. $O$ presente artigo pretende mostrar como Vygótski, além de ter abordado a arte que lhe era contemporânea em textos críticos, repercutiu (de forma produtiva e crítica) a inestimável contribuição da nascente teoria literária fundada com o Formalismo russo.

8 VYGÓTSKI, 2015, p. 199.

9 Idem, p. 203. 


\section{A Escola Formal nos estudos literários}

O fenômeno mais importante para os estudos de literatura no começo do século XX foi indubitavelmente a emergência da chamada Escola Formal dos estudos literários. Ela se organizou a partir de dois núcleos: o Círculo de Linguística de Moscou, fundado em 1915, e a Sociedade para o Estudo da Linguagem Poética de Petrogrado (OPOIAZ), fundada em 1916. Os primeiros teóricos dessa corrente tinham por objetivo libertar a palavra poética das tendências filosóficas e religiosas que marcavam o pensamento simbolista sobre a arte..$^{10}$ Os principais alvos dos ataques formalistas foram a filosofia da arte simbolista e a teoria do linguista Aleksandr Potebniá (1835891). A noção de que "arte é pensar em imagens", pedra angular dessa teoria, indica que, anteriormente, a grande matriz da literatura era a metáfora. Para Potebniá, o pensamento por imagens é o traço distintivo da produção literária: "A imagem de Potebniá (tanto quanto a dos românticos) é uma categoria visual, complementada na percepção individual e relacionada com o processo criativo"11. Dessa noção decorrem as ideias de que a imagem facilita a compreensão do conteúdo e, dessa forma, o prazer estético é resultado de uma economia de esforços. Assim Viktor Chklóvski (1893-1984), um dos expoentes do Formalismo, resumiu a compreensão sobre saber o fazer poético vigente até aquele momento:

Todo o trabalho das escolas poéticas consiste na acumulação e revelação de novos procedimentos de disposição e elaboração do material verbal; ele está muito mais na disposição de imagens do que na sua criação. As imagens estão dadas; na poesia, as imagens são mais recordadas do que utilizadas como forma de pensar. ${ }^{12}$

Tributário da tradição de Wilhelm von Humboldt (1769-1859), Potebniá segue "a trilha romântica da linguística que colocava ênfase nos fatores individuais e criativos no desenvolvimento

10 EIKHENBAUM, 1987.

11 POMORSKA, 1972, p. 30.

12 CHKLÓVSKI, 2019, p. 156 
da linguagem" ${ }^{13}$ Os formalistas, por sua vez, buscaram estabelecer uma distinção entre linguagem poética e linguagem prática. Olhavam a obra literária menos de um ponto de vista genético (isto é, que buscava as origens e fontes da literatura na biografia do artista ou em elementos sociais e históricos ou seja, em causas extraliterárias) e mais de uma perspectiva fenomenológica, por assim dizer. A busca era pela especificidade do material literário tal como ele se apresenta. Assim, os teóricos do método formal ressaltaram o "produto em si mesmo, não no processo ou a gênese desse produto; concentram-se sobre os fatores estritamente literários, artísticos ou linguísticos e não sobre aspectos que estão além da esfera do 'texto' em si". ${ }^{14}$

Contudo, não se pode dizer que o Formalismo corresponda teoricamente à doutrina do final do século XIX da "arte pela arte", uma vez que sua estética é descritiva (e não metafísica), enfatizando o objeto literário em sua materialidade, ao mesmo tempo em que pressupõe a autonomia dos estudos literários. ${ }^{15}$ A peculiaridade da literatura deveria ser buscada na própria obra e não no psiquismo do leitor ou do autor, por exemplo. Em consequência, conceitos como os de "intuição", "imaginação" e "gênio" foram descartados por esta corrente. Para Viktor Jirmúnski (1891-1971), a literatura dispõe de "todo um nexo de relações formais e lógicas inerentes à linguagem e impossíveis de ser expressas em qualquer outro campo da arte".16

Nesse sentido, Chklóvski faz a distinção entre dois tipos de imagens: aquela que age como forma de pensamento prático, ou seja, como forma de unir objetos, e aquela que tem por objetivo intensificar a impressão dos sentidos. O uso de imagens deixa de ser central e torna-se um entre outros procedimentos artísticos dos quais o poeta pode lançar mão. $O$ objetivo desses procedimentos é "intensificar a sensação das coisas", ${ }^{17}$ sendo

13 POMORSKA, 1972, p. 20.

14 Idem, p. 29.

15 ERLICH, 1981, p. 171.

16 Apud ERLICH, 1981, p. 174.

17 CHKLÓVSKI, 2019, p. 158. 
que "as coisas" podem ser as próprias palavras ou os sons de uma obra. Chklóvski rebate a noção de economia de esforços resultante do uso de imagens ao lembrar que as leis que regem o uso prático da linguagem são opostas àquelas que regem seu uso poético, uma vez que "se na 'prosa' informativa, a metáfora tem por objetivo aproximar o tema do público [...] na poesia ela serve para intensificar o efeito estético pretendido. [...] a imagem poética 'torna estranho' o habitual ao apresentá-lo sob uma nova luz, ao colocá-lo num contexto inesperado". ${ }^{18}$ Essa linha de raciocínio conduz à formulação de um conceito chave do Formalismo: o estranhamento (ostraniénie).

Essa qualidade do pensamento sugere não somente o caminho da álgebra, mas também a escolha de símbolos (letras, em particular as iniciais). Nesse método algébrico de pensar, os objetos são concebidos em seu número e espaço; não são vistos, são apenas reconhecidos a partir de seus primeiros traços. [...] No processo de algebrização, de automatização do objeto, obtemos a máxima economia das forças perceptivas [...] O que chamamos arte, então, existe para retomar a sensação de vida, para sentir os objetos, para fazer da pedra, pedra. A finalidade da arte é oferecer o objeto como visão e não como reconhecimento: o procedimento da arte é de ostraniénie dos objetos, o que consiste em complicar a forma, em aumentar a dificuldade e a duração da percepção. O ato da percepção é, na arte, um fim em si, e deve ser prolongado. A arte é um meio de viver a feitura do objeto; aquilo que já foi feito não interessa em arte. ${ }^{19}$

Desse modo, a imagem empregada como procedimento artístico não tem por finalidade produzir no leitor o reconhecimento daquilo que ela representa, mas permite que o objeto seja percebido de uma forma especial, permite que ele seja visto. A arte, vista em seu caráter particular, passa a ser analisada menos a partir da oposição entre forma e conteúdo e mais precisamente como organização de um determinado material por meio de procedimentos poéticos. Para Eikhenbaum, os formalistas contribuíram para que se verificasse que "a especificidade [da arte] se expressa não nos elementos in-

18 ERLICH, 1981, p. 176.

19 CHKLÓVSKI, 2019, p. 160-161. 
troduzidos na obra, mas na utilização particular que se faz deles" ${ }^{20}$ Assim, por material entende-se tudo aquilo que o artista encontra pronto (palavras, sons, fábulas correntes), ao passo que a forma é a organização desse material. Nas palavras de Eikhenbaum:

A concepção de forma aparece em um novo sentido: não como invólucro, mas como uma totalidade, algo concreto e dinâmico, que carrega em si mesmo um conteúdo, fora de quaisquer correlações. Nisso expressou-se um afastamento decisivo em relação aos princípios do Simbolismo, para o qual "por meio da forma" deve transparecer algo "substancial". Assim, superou-se também o "estetismo" como apreciação de alguns elementos da forma conscientemente divorciados do "conteúdo". ${ }^{21}$

Importante ressaltar o dinamismo atribuído por Eikhenbaum ao conceito de forma literária, de modo que não se caia numa visão simplista do Formalismo como uma corrente ocupada somente em estudar os aspectos exteriores de uma obra, desprovidos de sentido e significado. A partir da noção de literariedade (literatúrnost), termo de Roman Jakobson, os formalistas buscaram assegurar a especificidade e a autonomia dos estudos literários. Como observa Erlich:

Isso significava que a arte é um modo distinto de empreendimento humano, não completamente explicável em termos de outras esferas da experiência, ainda que próximas a elas. Implicava a noção de "literariedade" não como um único aspecto pertinente da literatura, nem simplesmente um dos seus componentes, mas uma propriedade estratégica que informa e permeia a totalidade da obra, o princípio da integração dinâmica, ou, para usar um termo da psicologia moderna, uma Gestaltqualität. Consequentemente, o "ethos" aparece não somente como uma camuflagem pseudo-realista para o "real", mas como um elemento bona fide da estrutura estética e, como tal, um objeto legítimo do estudo literário, caso ele seja examinado do ponto de vista de sua "literariedade", ou seja, dentro do contexto da obra literária. E, final-

20 EIKHENBAUM, 1987, p. 384.

21 Idem, p. 385. 
mente, a obra em si era definida não como um conjunto de procedimentos, mas como uma estrutura complexa e multidimensional, integrada pela unidade do propósito estético. ${ }^{22}$

Se, nos primeiros anos, o Formalismo esteve preocupado em distinguir literário e não literário e, para tanto, olhou a obra independentemente de quaisquer nexos sociais, psicológicos e filosóficos, com o passar do tempo, outros temas foram sendo incorporados. Em seu balanço da Teoria do Método Formal, Eikhenbaum, aponta cinco momentos, considerando a evolução dos objetos de estudo: 1) oposição entre língua poética e língua cotidiana; 2) do conceito de forma ao conceito de procedimento e, enfim, à noção de função; 3) noção de ritmo como fator construtivo do verso; 4) o material constitui a motivação e participa da construção, ainda que sempre dependa da dominante construtiva; 5) evolução das formas, estudo da história literária. ${ }^{23}$

É principalmente pelo trabalho de Iúri Tyniánov (1894-1943) que o Formalismo chega aos conceitos de função e série literárias, que permitem com quem o escopo da nova ciência da literatura se expanda. O estudo teórico inicial, responsável por produzir novas categorias e conceitos para uma análise imanente da obra literária, se expande e chega ao campo histórico. Com Tyniánov, a ideia de série literária encontra sentido e particularidade em correlação com outras séries concorrentes na vida social:

O estudo da evolução da literatura é possível apenas mediante uma relação com a literatura como série, como sistema que estabelece correspondência com outras séries, que é condicionado por elas. O exame deve partir da função construtiva para a função literária, da literária à verbal. Ele deve esclarecer a interação evolutiva da série literária com as outras séries correspondentes mais próximas, e não com as mais distantes, mesmo que sejam as principais. $O$ significado dominante dos principais fatores sociais não apenas não é rejeitado por ele, mas deve ser explicado em sua totalidade justamente na questão da evolução da literatura, assim o estabelecimento direto da "influência" dos principais

22 ERLICH, 1981, p. 198-199.

23 EIKHENBAUM, 1987, p. 407-408. 
fatores sociais substitui o estudo da evolução da literatura pelo estudo da modificação das obras literárias, de sua deformação. ${ }^{24}$

O Formalismo partiu de uma tentativa de conceber uma ciência literária nos termos das ciências naturais - ou seja, isolando o objeto e buscando compreendê-lo de forma abstraída de qualquer contexto seu funcionamento - para um entendimento mais dialético e não unilateral das relações entre literário e não literário. O fenômeno literário deixa de ser uma totalidade estática cujas leis devem ser estabelecidas de uma vez por todas. E a literatura como processo (e não fenômeno) deve ser apreendida não como "evolução planificada, mas por saltos; não como desenvolvimento, mas como deslocamento". 25

\section{A leitura vygotskiana do Formalismo Russo em Psicologia da arte}

Psicologia da arte foi o primeiro livro de natureza científica escrito por Vygótski. É, por assim dizer, sua primeira psicologia. Em linhas gerais, sua proposta consistia em derivar da obra artística uma psicologia que lhe fosse própria, em oposição à frequente tentativa de aplicar conceitos psicológicos prontos para compreender a arte. Vygótski elegeu como objeto de estudo a reação estética. Contudo, ao investigá-la, estabeleceu um método indireto, por ele denominado método objetivo- analítico. Assim, a reação é aferida não diretamente no receptor concreto, mas reconstituída a partir das caraterísticas específicas - formais - do objeto estético que a produz, isto é a obra artística. Trata-se de uma proposta com visíveis paralelos com o Formalismo. Se tomarmos o exemplo da noção de estranhamento chklovskiana: nesse caso, o objeto se insere

24 TYNIÁNOV, 1929, p. 47.

25 TYNIÁNOV, 1929, p. 6. Interessante observar que a ideia de que o desenvolvimento se dá não em linha reta, mas por saltos qualitativos, está presente também em Vygótski, por exemplo em sua crítica à teoria do desenvolvimento de Bühler (cf. VYGOTSKY, 1982, p. 196-209). 
também no campo da reação, a qual também é deduzida indiretamente, mediante a análise dos indícios formais. ${ }^{26}$

O impulso que levou Vygótski a construir sua psicologia da arte é muito semelhante às aspirações que nortearam a organização do Formalismo, em particular no que diz à orientação de ambos para a objetividade, para a abstração do particular em prol da elaboração de leis gerais. Em seu projeto de psicologia da arte, Vygótski afirma que ter buscado:

[...] deduzir as leis da psicologia da arte mediante a análise de uma fábula, um romance e uma tragédia. [...] Estudei nelas o que constitui a base de toda a arte: a natureza e o mecanismo da reação estética. Apoiei-me nos elementos gerais da forma e do material inerentes a toda arte. [...] essa análise pressupõe fazer abstração dos traços concretos da fábula com um gênero determinado para concentrar o esforço na essência da reação estética. [...] os princípios que explicam a arte nos falam de uma reação que de fato nunca ocorreu de forma pura. ${ }^{27}$

Nos escritos de segunda metade dos anos 1920, Vygótski discute sua compreensão de que a psicologia é um campo em crise, cindido entre duas tendências irreconciliáveis: uma psicologia científica, materialista e objetiva e uma psicologia metafísica, idealista e subjetiva. ${ }^{28} \mathrm{~A}$ defesa de Vygótski da primeira bem como sua rejeição da metafísica e do subjetivismo são análogas à busca formalista por uma delimitação e rigor do campo dos estudos literários. Para tanto, os formalistas se apoiaram no modelo de conhecimento das ciências naturais. Os fenômenos da cultura deviam deixar de ser examinados por pseudociências, pois são tão suscetíveis à análise e compreensão objetiva quanto quaisquer fenômenos da natureza:

É claro que esse processo será muito mais difícil e doloroso do que na esfera das ciências naturais, pois aqui o fenômeno

26 Em resposta a uma possível acusação de "desvio psicológico", Erlich lembra que no Formalismo "a ênfase está localizada não nas associações idiossincráticas do leitor individual, mas nas qualidades inerentes à obra de arte, capazes de suscitar certas respostas 'intersubjetivas'" (ERLICH, 1981, p. 178-9). Para os formalistas, assim como para Vygótski, o sujeito da reação estética/estranhamento não é empírico, mas uma categoria abstraída.

27 VIGOTSKI, 2004, p. 371-372.

28 VYGOTSKY, 2012. 
estudado é dado como experiência interna e sua integridade individual multiforme é vivenciada de maneira muito mais plena e clara do que os eventos do mundo exterior, dirigidos a nós como que de por um de seus aspectos. Contudo, não há dúvidas de que a ciência em seu desenvolvimento irá superar essas dificuldades e encontrará o caminho para o estudo isolado dos fatos em seus elementos constituintes. ${ }^{29}$

Também o desenvolvimento ulterior da psicologia vygotskiana e do Formalismo apresentam características análogas: a ideia de função (literária e psíquica) e de desenvolvimento (desenvolvimento psíquico e evolução literária) aparecem apenas posteriormente. A psicologia da arte de Vygótski pertence a um período considerado a pré-história de sua teoria, hoje conhecida como psicologia histórico-cultural. Nos trabalhos escritos entre 1927 e 1930, Vygótski desenvolveu o conceito de mediação por signos e de funções psicológicas superiores, considerando que elas se desenvolvem a partir das relações sociais entre indivíduo e meio. Do estudo isolado das funções, Vygótski, depois de 1930, estabelece a noção de sistemas psicológicos, ou seja, analisa as interconexões entre as funções e desenvolve uma metodologia de investigação por unidades, como sentido, significado e vivência. ${ }^{30}$ Compare-se a isso a passagem do estudo isolado dos procedimentos literários (como o estranhamento) ou do som no verso, e o posterior desenvolvimento dos conceitos de fato e série literária. ${ }^{31}$

A obra Psicologia da arte é dividia em quatro partes: 1) metodologia do problema; 2) crítica; 3) análise da reação estética; e 4) psicologia da arte. Na primeira parte, o autor estabelece as bases científico-metodológicas de seu estudo, com destaque para a explicitação de suas fontes marxistas (particularmen-

29 ENGELGARDT, 1927, p. 111.

30 Cf. DAFERMOS, 2018.

31 A analogia entre o desenvolvimento da psicologia vygotskiana e o Formalismo não pretende ocultar as profundas diferenças entre um e outro campo. Objetiva-se, antes, mapear semelhanças em termos dos anseios e do ambiente epistemológico que atravessa ambos. Tanto um como outro estão imbuídos da tarefa de delimitar um campo de estudo autônomo dotado de consistência científica e objetividade. E, nesse processo, ambos complexificam o entendimento do objeto em questão. 
te Bukhárin e Trótski) ${ }^{32}$ e a definição do método objetivo analítico. Em "Crítica", Vygótski discute três teorias sobre a arte vigentes à época: a teoria de Potebniá, o Formalismo russo e Psicanálise. Em cada um desses capítulos, o autor faz uma detida apreciação crítica, que leva em conta as potencialidades de cada teoria e aponta suas limitações e impasses.

No capítulo 3, "A arte como procedimento", Vygótski faz um balanço essencialmente positivo das conquistas do Método Formal até aquele momento. Com efeito, o deslocamento do foco do estudo da obra literária para a forma condiz com a preocupação que norteia a psicologia da arte vygotskiana de derivar a especificidade da reação estética daquilo que é especificamente artístico na obra (ou seja, de sua forma). ${ }^{33}$

A ideia formalista de que a organização do material na arte se dá por força de um condicionamento estético, isto é, por objetivos exclusivamente artísticos, é também integralmente aceita por Vygótski, que rejeita a instrumentalização da arte em favor de fins cognitivos ou morais - uma ideia defendia também em "Educação estética". ${ }^{34}$ Os personagens numa obra literária não podem ser explicados pela psicologia, pois "os sentimentos também vêm a ser apenas o material ou procedimento da representação", ${ }^{35}$ ou seja, as leis da psicologia não explicam a arte, mas o material psicológico é reconfigurado esteticamente. Dessa tal perspectiva, decorre profundo antipsicologismo do Formalismo, ou, nas palavras de Eikhenbaum, seu caráter suprapsicológico. ${ }^{36}$

32 É preciso mencionar que as citações tanto a Trótski quanto a Bukhárin foram censuradas da maioria das edições russas dessa obra (das quais foram feitas as traduções para outros idiomas, inclusive o português). Para uma versão que não omite tais referências, cf. VYGÓTSKI, 2001.

33 Veja-se, por exemplo, como Vygótski define o sentido de seu método: "da forma da obra de arte, passando pela análise funcional dos seus elementos e da estrutura, para a recriação da resposta estética e o estabelecimento de suas leis gerais" (VIGOTSKI, 2001, p. 27, grifo nosso)

34 VIGOTSKI, 2004, p. 232-263.

35 VIGOTSKI, 2001, p. 62.

36 Cf. Eikhenbaum, apud VIGOSTKI, 2001, p. 63. 
Se, por um lado, Vygótski entende que a obra de arte não deve ser explicada nos termos de um aparato teórico psicológico pré-existente, alheio à especificidade da linguagem poética, por outro lado, para o autor, a compreensão do funcionamento e da função da arte não pode prescindir de uma explicação psicológica. Se a Escola Formal representou um enorme avanço no entendimento da materialidade artística ao voltar-se às obras com um olhar objetivo capaz de destrinchar de que, afinal, é feita a literatura, a explicação dada pelos formalistas para o emprego dos procedimentos, ao fim e ao cabo, padece ironicamente de um lamentável "hedonismo elementar" ${ }^{37} \mathrm{~A}$ crítica vygotskiana merece ser citada na íntegra:

[...] a teoria dos formalistas cai numa surpreendente contradição consigo mesma, quando começa afirmando que em arte não importam os objetos, o material, o conteúdo, e termina afirmando: o fim da forma artística é "sentir o objeto", "fazer da pedra pedra", isto é, experimentar de modo mais intenso e agudo aquele mesmo material de cuja negação nós começamos. Graças a essa contradição, perde-se a verdadeira importância das leis do estranhamento, etc., descobertas pelos formalistas, uma vez que o princípio do estranhamento acaba sendo a mesma percepção do objeto, e esse defeito básico do formalismo - a não compreensão do sentido psicológico do material - leva-o à mesma unilateralidade sensualista como a não compreensão da forma levou os partidários de Potebniá à unilateralidade intelectualista. Os formalistas admitem que em arte o material não desempenha nenhum papel [...] Contudo, é fácil nos convencermos de que cada época tem uma relação não só de temas proibidos, mas também de terma a serem elaborados por ela e que, consequentemente, o próprio tema ou material da construção nem de longe são indiferentes em termos de efeito psicológico do todo da obra de arte. ${ }^{38}$

Vygótski reconhece que essa falha não se aplica a todo Formalismo. ${ }^{39}$ Aponta, por exemplo, como Viktor Jirmúnski en-

37 VIGOTSKI, 2001, p. 72.

38 Idem, p. 66, grifo nosso.

39 Evidentemente o comentário de Vygótski se aplica apenas à produção existente até aquele momento, ou seja, até 1925. Não inclui, assim, muitos dos desdobramentos dessa escola discutidos na seção anterior. 0 texto "Sobre a evolução literária", de Tyniánov, por exemplo, é de 1927. Em comentário à Psicologia da arte, Viatchseláv Ivánov alerta que a 
tende a obra como sistema estético condicionado a uma tarefa artística, sendo que o procedimento é o método e não um fim em si mesmo. ${ }^{40}$ Além disso, Vygótski retoma o filósofo alemão Broder Christiansen, cuja obra Philosophie der Kunst [Filosofia da arte] foi uma das bases para a construção do Formalismo, como um autor que reconhece a importância do material na síntese do objeto estético. ${ }^{41}$ Para reforçar o significado psicológico do material, Vygótski argumenta que a deformação deste pressupõe uma inevitável deformação da própria forma.

Ademais, Vygótski discorda do pressuposto formalista de que o objetivo da arte seja a percepção da forma (visão e não reconhecimento, como diria Chklóvski). Essa valorização da percepção como um fim em si mesmo revela, para o autor, a "pobreza psicológica" e o hedonismo kantiano ${ }^{42}$ do Formalismo. Em contraposição a essa ideia, o Vygótski vê na arte um sentido biológico, algo como a sublimação freudiana, mas com ênfase em sua orientação para o futuro. Para Vygótski, ao sistematizar e desenvolver o campo das emoções humanas, a arte organiza o comportamento futuro do homem: "a arte é antes uma organização do nosso comportamento visando o futuro, uma orientação para o futuro, uma exigência que talvez nunca venha a concretizar-se, mas que nos leva a aspirar acima de nossa vida o que está por trás dela". ${ }^{43}$ Muito próximos no olhar atento à especificidade da linguagem artística, o pensamento de Vygótski se afasta do dos formalistas no que diz respeito ao entendimento sobre as relações entre arte e sociedade, algo que se deve ao impacto de interlocutores no pensamento do psicólogo, em particular de teóricos marxistas.

crítica vygotskiana diz respeito mais especificamente à obra inicial de Chklóvski (cf. VIGOTSKI, 2001, p. 351). Considere-se, por exemplo, que Chklóvski chegou a fazer algo com uma crítica genética, com estudo de manuscritos, cadernos de rascunhos. Sua intenção, porém, é "demonstrar como o que está em seu início (o material) se vê de tal maneira alterado, que o realmente decisivo em arte são as transformações que têm lugar durante o processo de criação artística" (ORTÍ, 2008, p. 128).

40 VIGOTSKI, 2001, p. 66.

41 Idem, p. 67.

42 Segundo Nunes (2002, p. 13), a experiência estética de Kant está fundada em três princípios: aconceptualidade (evocada aqui por Vygótski), desinteresse (caráter contemplativo) e autotelia (finalidade intrínseca).

43 VIGOTSKI, 2001, p. 320. 


\section{Considerações finais}

A legitimidade e fundamento das críticas de Vygótski pode ser constatada no fato de que os próprios formalistas se viram impelidos a avançar em suas elaborações e superar as limitações das ideias iniciais, ${ }^{44}$ fato que se tornou possível dado o caráter inacabado e provisório da própria teoria, que surgiu mais como um conjunto de hipóteses a serem testadas do que um método rígido, como explica Eikhenbaun:

O elemento evolutivo é muito importante para a história do método formal. [...] Não tínhamos, e continuamos não tendo, qualquer doutrina ou qualquer sistema completamente elaborado. A teoria é somente uma hipótese de trabalho em nossas investigações. [...] Preferimos estabelecer princípios concretos e nos atermos a eles na medida em que podem ser aplicados a um determinado material. Mas se esse material exige uma complexificação ou uma modificação dos nossos princípios, sem duvida isso será feito. ${ }^{45}$

A partir do exposto, pode-se concluir que a crítica vygotskiana reconhece e incorpora o potencial produtivo da orientação dos pressupostos formalistas, ao mesmo tempo em que aponta suas limitações e contradições internas. Tanto os representantes da Escola Formal como o psicólogo soviético assumiram posições semelhantes: a) buscaram entender a arte em termos de sua relativa autonomia quanto a fatores extraestéticos, b) concentraram-se no estudo da reação estética não como fenômeno empírico, mas como fórmula abstraída da organização formal do material na obra; c) enfatizaram a necessidade de diferenciar estético de não estético e de compreender a especificidade da arte (linguagem poética versus linguagem prático-cotidiana, para os Formalistas; reação comum versus reação estética, no caso de Vygótski).

O principal ponto de convergência entre a Escola Formal e a psicologia da arte vygotskiana reside na metodologia de am-

44 HANSEN-LÖVE, 2001, p. 413-414. Ainda a respeito da relevância da posição vygotskiana, observa-se o fato de que a crítica do psicólogo tenha merecido destaque e um excelente comentário no monumental estudo do eslavista austríaco Åge Hansen-Löve sobre o Formalismo Russo.

45 EIKHENBAUM, 1987, p. 375-376. 
bos, isto é, a abordagem imanente da obra, que em Vygótski origina-se ainda no ensaio sobre Hamlet (de 1915). ${ }^{46}$ Os exemplos de análise oferecidos por Vygótski na terceira seção do livro são, para todos os efeitos, ótimas análises formalistas. Elas partem do pressuposto de as obras se organizam em termos de uma contradição entre forma e conteúdo, que se resolve na reação estética (ou catarse, termo que Vygóski toma de Aristóteles). Um exemplo evidente de ecos formalistas é a análise da novela "Leve alento" de Ivan Búnin, ${ }^{47}$ totalmente baseada nas noções de fábula e siujet, desenvolvidas originalmente pelo formalista Boris Tomachévski (1890-1957).

Contudo, as análises vygotskianas estão inseridas num entendimento mais amplo da função da arte, explicitado apenas nos capítulos finais da obra. Para Vygótski, a teoria formalista é extremamente profícua na definição do como? da arte, mas menos efetiva na compreensão do seu para quê?. O sentido da arte, segundo Liev Semiónovitch, só poderá ser explicado em termos psicológicos. ${ }^{48}$ Para Hansen-Löve,

Aquilo que na reconstrução do modelo reducionista da Fase 1 é designado como "efeito secundário/procedimento", é tomado por Vygótski como objeto fundamental da análise psicológica da arte: a interdependência entre os afetos estéticos (a estrutura emocional) e a fantasia (a estrutura da imaginação) que escapa aos limites da percepção física (Sensação 1) e adentra o campo da comunicação social, em que a arte atua como "técnica social do sentimento".49

Segundo Iarochévski, ${ }^{50}$ Vygótski via na construção artística não um objetivo em si mesmo, mas um meio para a realização e um objetivo social-psicológico. Assim, Vygótski não apenas constata a autonomia da série estética, mas "atribui-lhe um

46 HANSEN-LÖVE, 2001, p. 414.

47 Cf. capítulo 7 de Psicologia da arte (VIGOTSKI, 2001, p. 177-206).

48 Também Laferrière reconheceu a "miopia psicológica" do Formalismo, por exemplo, no fato de que Chklóvski mostrou-se incapaz de perceber a dinâmica psicológica subjacente ao paradoxo familiaridade/estranhamento. Para esse autor, contudo, a chave para a compreensão de tal dinâmica é psicanalítica, expressa no paradoxo freudiano Heimlich/ Unheimlich (LAFERRIÈRE, 1976).

49 HANSEN-LÖVE, 2001, p. 412

50 IAROCHEVSKI, 1998, p. 439. 
campo independente no âmbito da comunicação ideológica, que se liga a um campo do psiquismo do homem social também independente, que ele caracteriza como sua 'esfera do sentimento"'.51 Trata-se de um passo distante não apenas do Formalismo da época, mas mesmo dos desenvolvimentos posteriores dessa escola, uma vez que seus representantes não chegam a explicitar inteiramente as implicações ideológicas de seus postulados nem revelam uma visão de história mais acabada.

A superação da estética simbolista, preponderante nos escritos iniciais de Vygótski, conforme discutido na primeira seção deste artigo, é análoga ao movimento realizado pelo próprio Formalismo. Assim, na década de 1920 esta corrente aparece como um interlocutor fundamental para suas elaborações no campo da psicologia da arte, constituindo um diálogo central para originalidade do pensamento vygotskiano. Não será exagero afirmar, assim, que a psicologia da arte de Vygótski é largamente tributária dos avanços conquistados pela Escola Formal, em especial por sua aspiração objetivista.

Como é característico de sua obra como um todo, Vygótski se mostra um observador atento dos desdobramentos teóricos de sua época. Isso se evidencia em seus comentários originais sobre a psicologia da Gestalt, a teoria de Piaget, a Psicanálise, entre outros. Ao ler essas teorias criticamente, o autor mapeia suas limitações e impasses e propõe uma superação dialética deles. No caso analisado neste artigo, a incorporação de pressupostos formalistas, atravessada por uma perspectiva histórico-dialética da arte conferiram à psicologia da arte vygotskiana uma potência e originalidade ainda pouco exploradas tanto no campo dos estudos literários como pela própria psicologia.

51 HANSEN-LÖVE, 2001, p. 412-413. 


\section{Referências bibliográficas}

CAVALIERI; A. VASSINA; E. "O simbolismo no teatro russo nos inícios do século XX: faces e contrafaces". In: CAVALIERI, A.; VÁSSINA, E.; SILVA, N. Tipologias do Simbolismo nas culturas russa e ocidental. São Paulo: Humanitas, 2005. p. 107-141 CHKLÓVSKI, V. "Arte como procedimento". Tradução David Molina. RUS, v. 10, n. 14., 2019.

DAFERMOS, M. Rethinking Cultural-Historical Theory. Singapura: Springer, 2018

DOBKIN, S. "Veka i dni" [Eras e dias]. In: Levitin, K. Litchnostio ne rojdaiutsa [Não se nasce uma personalidade]. Moscou: Nauka, 1990.

EIKHENBAUM, B. "Teoria formalnogo metoda” [Teoria do método formal]. In: O literature [Sobre a literatura]. Moscou: Soviétski Pissátiel, 1987

ENGELGARDT, B. Formalni metod $v$ istorii literatury [O método formal na história da literatura]. Leningrado: Academia, 1927

ERLICH, V. Russian Formalism: History and Doctrine. New Haven e Londres: Yale UP, 1981.

HANSEN-LÖVE, A. Ruski formalizm [Formalismo russo]. Moscou: Iazyki russkoi kultury, 2001, p. 414.

IAROCHEVSKI, Mikhail Grigórevitch. "Vygótski kak issledovatel problem psikhologii iskusstva". [Vygótski como pesquisador do problema da psicologia da arte]. In: Psikhologiia Iskusstva [Psicologia da arte]. Rostov do Don: Fenikc, 1998. LAFERRIÈRE, D. "Potebnja, Sklovskij, and the Familiarity / Strangeness Paradox". Russian Literature, v. 4, n. 2, 1976. p. 175-198.

NUNES, Benedito. Introdução à filosofia da arte. São Paulo: Ática, 2002.

ORTÍ, Pau Sanmartín. Otra historia del formalismo ruso. Madrid: Lengua de Trapo, 2008. 
POMORSKA, K. Formalismo e futurismo. São Paulo: Perspectiva, 1972.

TOLMACHOV, V. "Sobre as fronteiras do simbolismo". In: CAVALIERI, A.; VÁSSINA, E.; SILVA, N. Tipologias do Simbolismo nas culturas russa e ocidental. São Paulo: Humanitas, 2005. p. 15-33.

TYNIÁNOV, Iu. "O literaturnoi evoliutsii" [Sobre a evolução literária]. In: Arkhaisty i novatory [Arcaístas e inovadores]. Leningrado: Priboi, 1929.

VIGOTSKI, L. S. A tragédia de Hamlet, príncipe da Dinamarca. Tradução Paulo Bezerra. São Paulo: Martins Fontes, 1999. VIGOTSKI, L. S. "O significado histórico da crise na psicologia". In: Teoria e método em psicologia. São Paulo: Martins Fontes, 2004.

VIGOTSKI, Liev Semionovitch. Psicologia da arte. Tradução Paulo Bezerra. São Paulo: Martins Fontes, 2001. VYGÓTSKI, L. S. “Monna Vanna”. Veresk, n. 1, 1922.

VYGÓTSKI, L. S. "Teatro e revolução", o Percevejo Online, v. 7, n. 2, 2015.

VYGÓTSKI, L. S. Vstupitelnaia statia k russkomy perevodu knigui K. Biulera "Otcherk dukhovnogo razvitiia rebionka" [Prefácio à tradução russa do livro de K. Bühler "Ensaio sobre o desenvolvimento espiritual da criança]. In Sobránie Sotchiniênii $v 6$ tomakh. Tom 1. [Obra reunida em 6 volumes. Volume 1] Moscou: Pedagóguika, 1982.

VYGÓTSKI, L. S. Analiz estetítcheskogo reaktsii: traguédia o Gamlete, printse Datsom U. Chekspira i Psikhologuiia iskusstva. Moscou: Labirint, 2001.

VYGOTSKY, L. S. "The science of psychology". Journal of Russian and East European Psychology, v. 50, n. 4, 2012.

Recebido em: 07/07/2020

Aceito em: 05/08/2020

Publicado em setembro de 2020 